\title{
Biogeochemistry statement on \#ShutDownSTEM and Black Lives Matter
}

\author{
Kate Lajtha $\cdot$ Sherestha Saini
}

Published online: 2 July 2020

(C) Springer Nature Switzerland AG 2020

Science, even our own field of biogeochemistry, is not immune to both conscious and unconscious bias, discrimination, silencing, and not hearing or choosing not to hear minority colleagues and voices. The history of these racist and discriminatory practices in science is discussed elsewhere, as the writers of this statement would not do justice to a discussion of this history. However, we recognize that we are part of the machine of science that has a publish or perish business model and that determines the voices that are heard, and published. We are part of the system by choosing editors, reviewers, and invited papers and issues. We both pledge our support to the Black Lives Matter movement while recognizing that pledging support is not enough. Like Springer, AAAS, AGU, and most science organizations, we acknowledge and support \#ShutDownSTEM, a grassroots movement that aims to "transition to a lifelong commitment of actions to eradicate anti-Black racism in academia and STEM."

How can we do better? We need the help of our community at large. We need advice and suggestions from our readers on how to be more inclusive, and how to diversify our Editorial Board and our Board of Readers. The point of \#ShutDownSTEM was to stop and take time to listen. All ideas are welcome-please email either of us directly:

Kate.Lajtha@oregonstate.edu

Sherestha.Saini@springernature.com

Our first action will be to provide a platform to black scientists and scientists of color to write editorials on their science, their experiences, their perspectives. We commit to listening, educating ourselves, and taking meaningful steps to amplify the voices of black students and researchers.

Kate Lajtha, Editor-in-Chief, Biogeochemistry.

Sherestha Saini, Senior Publishing Editor, Biogeochemistry.

Publisher's Note Springer Nature remains neutral with regard to jurisdictional claims in published maps and institutional affiliations.

\footnotetext{
K. Lajtha $(\bowtie)$

College of Agricultural Sciences, Oregon State

University, Corvallis, OR 97331, USA

e-mail: Kate.Lajtha@oregonstate.edu

S. Saini

Springer Nature, New York, NY, USA

e-mail: Sherestha.Saini@springernature.com
} 